detailed comparative work on the social and economic structure of the Inter-Lacustrine Bantu, and the planning of joint publications in this field.

Discussions were held on the kinship, territorial, and political organizations of the following: Uganda-Ganda (A. B. Mukwaya); Nyoro (J. Beattie); Soga (L. A. Fallers); Toro (B. K. Taylor): Tanganyika-Ha (J. Scherer); Haya (P. Reining); Zinza (J. W. Tyler). A scheme for the comparative study of political systems outlined by the Director was also discussed as well as a paper by $\mathrm{Dr}$. K. Wachsmann on traditions of tribal migration among the Inter-Lacustrine Bantu.

Papers on the following tribes in Kenya were also read: 'Social structure of the Boran' (P. T. W. Baxter) and 'Marriage among the Kikuyu' (J. Fisher).

Professor F. Lorimer of the Amierican University, Washington, D.C., was present at one session and outlined a scheme for the collection of demographic data in East Africa. He was anxious to acquire additional information on maternity histories in areas of particularly low or particularly high fertility according to the 1948 census and suggested forms of village survey that might be conducted to this end.

\title{
Symposium on Popular Education in Africa
}

ON 3 I March, I and 2 April 1952 a symposium on Popular Education in Africa-' Literacy Campaigns and After-care '- was held at Leyden, organized by the African Institute, Leyden (Afrika-Instituut Leiden). Fourteen experts from Belgium, France, Great Britain, Kenya, the Netherlands, and Senegal took part, as wcll as a representative of Unesco; Portugal sent an observer.

Memoranda, dealing with different aspects of the subject, were presented by Georges Balandier (France), Father A. Brys (Belgium), G. W. J. Drewes (the Netherlands), A. Gille (Belgium), Lucien Paye (France), Margaret Read (Great Britain), A. N. Tucker (Great Britain), J. van Baal (the Netherlands). Professor Drewes and Dr. Van Baal gave accounts of educational work carried out in the Netherlands Indies before the second world war and of problems in Netherlands New Guinea respectively.

A full report of the proceedings is to be published.

\section{Ethiopian Studies}

AN Institute for Ethiopian studies has recently been formed in Asmara and is temporarily accommodated at the Italian Catholic Mission, by kind permission of Bishop Marinoni.

The Chairman of the Institute is Avv. Felice Ostini (who was responsible for its foundation); Professor Sergio Ponzanelli is Vice-Chairman. Other members of the Managing Committee are: Abba Tewelde Medhin Joseph, Professor Tron (of the Swedish Mission), Sheik Mahmoud Nur Hussen, and Signor Michele Pollera.

The aim of the Institute is to promote and develop studies of Ethiopia; it intends to publish a multilingual Bulletin, in which progress will be reported.

The Institute is divided into the following sections: (I) Historical and archaeological studies; (2) Scientific (ethnological, anthropological, and biological) studies; (3) Philological studies; (4) Literary studies (including music and the arts); (5) Juridical and economic studies; (6) Religious studies.

Further information can be obtained from the Chairman of the Institute at P.O. Box I 144, Asmara. 